\title{
LA DETERMINACIÓN RETÓRICA DEL SER
}

\author{
ÁLVARO VALLEJO CAMPOS \\ Universidad de Granada
}

\begin{abstract}
RESUMEN: En el presente trabajo se pretende reflexionar sobre la ontología del discurso utópico platónico en la República. Platón opone la figura del filósofo gobernante, que es de quien depende que el proyecto sea realizable, a «los amantes de los espectáculos» y a «los hombres de acción». Todas estas figuras, que pertenecen a la sofística y la retórica, son en realidad "amantes de la opinión", de manera que la demarcación del verdadero filósofo supone defender contra estos una idea del arte de gobernar basada en la epistémē y en una concepción normativa del ser. De los diversos sentidos que tiene el ser en la ontología platónica, existencial, predicativo y veritativo, el proyecto platónico del arte de gobernar se fundamenta en una concepción normativa del ser, cuya perfección esencial no viene determinada por la nuda existencia, sino por la identidad y la unidad de la forma. La ontología platónica así definida, en unos términos que vienen determinados en gran medida por su discusión con la retórica, se convierte en el fundamento del paradigma para la construcción de la ciudad ideal, cuya validez no está condicionada por la existencia empírica de las cosas.
\end{abstract}

PALABRAS CLAVE: discurso utópico, retórica, ontología normativa, paradigma, ciudad ideal, Platón, Isócrates.

\section{The Rhetorical Determination of Being}

ABSTRACT: The aim of this article is to examine the ontology of utopian discourse in Plato's Republic. Plato defines the possibility of the philosopher ruler against the "sightlovers" and the "men of action". All these other kinds of men, that belong to the circles of the sophistic and rhetorical movement, are in fact described by Plato as «philodóxoi». This means that the demarcation of the true philosopher is founded against rhetoric in a theory of the art of government based on epistēme and on a normative conception of being. Among the different senses of being in Platonic ontology, existential, predicative and veridical, Plato's project of the art of government is founded in a normative conception of being, whose essential perfection is not based on mere existence but on the identity and unity of the form. Plato's ontology, so defined and highly determined by his discussion with rhetoric, becomes the foundation of the paradigm for the construction of the ideal city, whose validity is not determined by the empirical existence of things.

KEY WORDS: utopian discourse, rhetoric, normative ontology, paradigm, ideal city, Plato, Isocrates.

\section{LA RETÓRICA Y LA CRÍTICA PLATÓNICA DE LA DÓXA}

En el título de este trabajo se ponen en relación dos conceptos que rara vez, a mi entender, aparecen vinculados. Se trata, efectivamente, de la retórica y el ser. En mi análisis de esta cuestión voy a centrarme mayormente en la República de Platón, pero creo que a partir de esta obra podemos sacar consecuencias no solo para el pensamiento filosófico platónico, sino para una buena parte de la reflexión filosófica, que, inspirada en una ontología como la platónica, considera la existencia fáctica de las cosas como algo inesencial al ser. Es verdad que la palabra retórica o sus derivados tienen escasa presencia en esta obra (cfr. 548e5), pero no faltan referencias indirectas a ella, como veremos enseguida. Sin embargo, podría decirse que todo el diálogo constituye una situación 
retórica, pues se trata de persuadir, a los interlocutores de Sócrates o a los lectores, de toda una serie de principios que constituyen el núcleo doctrinal del pensamiento político de Platón. En realidad, como le dice Sócrates a Glaucón, a propósito de su disputa con Trasímaco, que centra ya todo el marco de la discusión posterior, se trata de que nos constituyamos en «jueces y oradores»

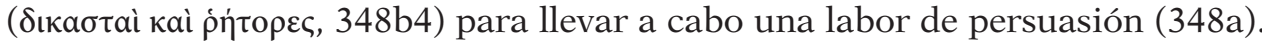
Y esto es justamente lo que pide Glaucón a Sócrates, al principio del libro II, quedar «verdaderamente persuadido» (ả $\lambda \eta \theta \tilde{\omega} \varsigma \pi \varepsilon \tilde{\sigma} \sigma a)$ de que es mejor la justicia que la injusticia. Adimanto toma la palabra después de su hermano, para exponer el realismo moral de la sociedad ateniense que cuestiona todos los discursos en defensa de la justicia. En su opinión si «desde niños hubiésemos sido persuadidos» (367a1-2) de los efectos beneficiosos de esta, no hubiese sido necesario andar vigilándonos y basar en la coerción social los fundamentos de la moralidad. De manera que toda la obra se abre con una exigencia de persuasión y la tarea que se divisa en el horizonte ante Sócrates es verdaderamente hercúlea, pues se trata nada menos que de abandonar muy arraigadas creencias sobre la moral y la justicia y sustituirlas en el ánimo de los interlocutores por otras mejor fundadas filosóficamente, como si el lector tuviera que constituirse en un juez que hubiera de juzgar el mérito de los discursos.

Difícilmente podría negarse que Platón tenga plena consciencia sobre la naturaleza retórica del escenario literario creado en su obra. En otros diálogos, como el Gorgias y el Fedro, reflexiona deliberada y explícitamente sobre la naturaleza de la retórica. Sin embargo, tenemos que reconocer que en la República hay escasas referencias explícitas al tema. Parece como si se hubiese contentado con crear un espacio retórico y dejara para otro momento la reflexión explícita sobre la naturaleza de la técnica retórica tan concienzudamente analizada en otras obras. Sin embargo, Platón sabía que los fundamentos del discurso utópico sobre los que iba a levantar los cimientos de la ciudad ideal, tenían que apartarse del núcleo teórico sobre el que se apoyaba la retórica y a esta cuestión, desde luego, sí que se hacen referencias explícitas y decisivas.

Me refiero naturalmente al tema de los defensores de la dóxa. Platón forja, efectivamente, la palabra ${ }^{1}$ philódoxos (480a6 y 12) para hacer referencia a «los amantes de la opinión» en unos textos donde se aborda precisamente la figura del filósofo gobernante, como la clave de bóveda que ha de soportar el edificio de la ciudad ideal. Constituye, como es sabido, la tesis más paradójica de la filosofía política de la República. Después de tratar de la igualdad de hombres y mujeres en las tareas de gobierno, y de la comunidad de mujeres e hijos, «la tercera ola» desencadenada por Sócrates es la figura del filósofo gobernante, que aparece como condición de posibilidad para la existencia de la ciudad ideal (V 473d). Sin embargo, esta tesis, que consiste en confiar el gobierno del estado a los filósofos, se aparta de una manera tan estridente del sentido común (cfr. 473e-474a), que Sócrates teme hacer el más grande de los ridículos y es

1 Cfr. Shorey, P., ad loc., The Republic, 2 vols., Cambridge, Mass., 1969 (1937). 
necesario llevar a cabo una elucidación de la figura del filósofo para disipar los prejuicios (cfr. V 473c-474a) que ponen en cuestión la posibilidad de su contribución al bienestar de la ciudad. De manera que Platón tiene que establecer un auténtico criterio de demarcación que deslinde la filosofía de otras prácticas y muestre las razones que le asisten a la hora de reclamar su derecho a ostentar el poder. Pero lo que tenemos que mostrar es la naturaleza retórica o más bien anti-retórica de la cuestión, lo cual viene a ser equivalente para el propósito que perseguimos. El gobierno del filósofo es una cuestión que Sócrates califica

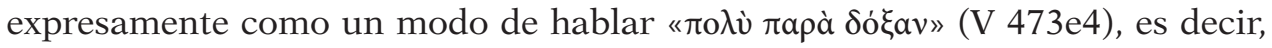
que se aparta mucho de la opinión común. De ahí que todo el problema de la posibilidad del gobierno del filósofo esté estrechamente vinculado con dos cuestiones de naturaleza eminentemente retórica: la primera es el problema de la dóxa, pero la segunda no lo es menos, porque se trata de desbrozar la naturaleza de los verdaderos filósofos, separándola de otras figuras con las que corría el peligro de confundirse. Sobre todo tenía que mostrar sus diferencias con el intelectual vigente en la cultura retórica de la época, porque este reclamaba igualmente para sí el título de la verdadera filosofía. Veremos enseguida que ambas cuestiones están perfectamente entrelazadas y que las dos nos llevan también directamente al problema del ser.

La cuestión consiste en esclarecer, como dice Sócrates, "a qué filósofos aludimos cuando nos atrevimos a afirmar que ellos deben gobernar» (V 474b). Platón quiere separarlos de otros candidatos que se atribuyen también a sí mismos el nombre de filósofos. A su juicio estos renuncian a una parte de la indagación, que para él es la más propia de esta actividad, el estudio teórico especulativo que se enseñaba en la Academia. En su obra titulada Contra los Sofistas, Isócrates a mi juicio ${ }^{2}$ tiene a Platón en su punto de mira, cuan-

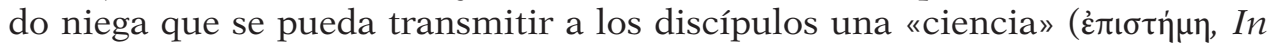
Soph. 3.4, 8.4) capaz de procurarles la felicidad, y duda sobre el valor formativo de las disputas dialécticas de los que prometen, como Platón, fundar en estas prácticas la adquisición de la "virtud y la moderación» (ả

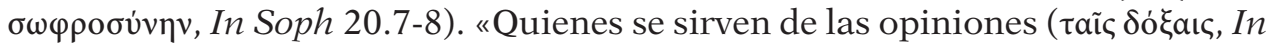
Soph., 8.3), dice él, aciertan más y llegan antes a acuerdos que los que proclaman estar en posesión de una ciencia», por lo que Isócrates no ve extraño que

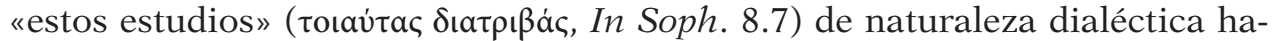
yan sido despreciados y se hayan considerado "charlatanería y mezquindad»

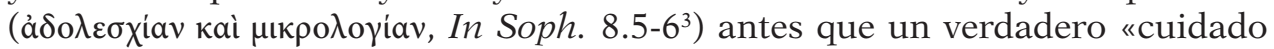

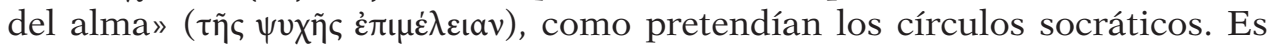

2 En esto estoy de acuerdo totalmente con JAEger, W., Paideia: los Ideales de la Cultura Griega, México, 1971, (1933-1945), págs. 842 y sgs.

3 Platón hace referencia al término adoleschía en pleno debate sobre la retórica en el $\mathrm{Fe}$ dro, cuando Sócrates afirma que las grandes artes necesitan «charlatanear y meteorologizar sobre la naturaleza» (270a). Isócrates utiliza la expresión adoleschía kaì mikrología en dos ocasiones, aunque en la Antídosis toma cierta distancia frente a esta acusación de la que eran objeto las prácticas dialécticas propias de la Academia (cfr. Antídosis 262.2). 
precisamente «este estudio» el que Platón reivindica en la República, utilizan-

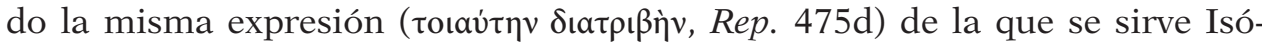
crates para denostar la concepción especulativa y dialéctica de la formación científica que preconizaba la Academia.

Lo que Isócrates discute a Platón es que pueda existir un arte o una ciencia en cuestiones políticas ( $\dot{\varepsilon} \pi \sigma \tau \dot{\mu} \mu \eta$, Hel. 9.3) o que haya una ciencia capaz de fundir en una única virtud disposiciones tan diferentes como son «el valor, la sabiduría y la justicia» (Hel.1.5-7). Pero ambos presupuestos son justamente el fundamento en el que se basa la pretensión esencial del pensamiento platónico, que precisamente por ello concede al filósofo el derecho a ostentar el gobierno del estado. Los tecnicismos lógico dialécticos propios del discurso filosófico son a juicio de Isócrates «inútiles para la acción» y algo "completamente apartado de las necesidades» vitales (Ant. 262-3). Él piensa que sobre los verdaderos asuntos que interesan en la vida humana la ciencia es imposible (Contra Sof. 3 y 8) y, en aquellos temas en los que es posible, todo lo más sirve como una especie de adiestramiento del alma (Ant. 266), carente de aplicaciones prácticas inmediatas. En su lugar, Isócrates rehabilita y moraliza la dóxa denostada por Gorgias $^{4}$ y la convierte no ya de hecho, sino de derecho en el fundamento de la persuasión retórica. Isócrates defiende, efectivamente, las virtualidades de la opinión tanto desde un punto de vista educativo como político. Refiriéndose críticamente a la filosofía y la dialéctica platónicas, su punto de vista es que es «mucho más importante opinar de manera sensata sobre cosas útiles que saber con exactitud cosas inútiles» $\left(\mathrm{Hel}\right.$. 5) ${ }^{5}$. La polémica con el platonismo parece traslucirse en su creencia de que no se podía llamar filosofía a una actividad que no era útil ni «para hablar ni para actuar», porque los que se dedican a «un estudio de esa naturaleza» ( cultivan una especie de ejercicio del alma o una actividad meramente prope-

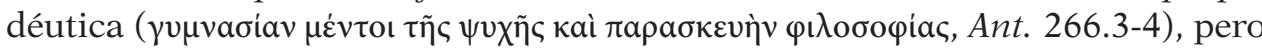
no la verdadera filosofía, que Isócrates identifica con el arte de los discursos y el conocimiento de las opiniones que resultan realmente útiles para lidiar con los grandes problemas del estado. A ese estado de opinión es al que se enfrenta Platón a la hora de dilucidar quiénes son los verdaderos filósofos a los que hay que entregar el gobierno del estado.

Independientemente de que podamos demostrar con mayor o menor verosimilitud la existencia de una polémica mutua entre ambos autores, dado que Isócrates nunca menciona a Platón en sus escritos y este no lo cita expresamente

4 Sobre las diferencias en relación a la dóxa entre Gorgias e Isócrates, véase nuestro «Conflicto en torno al lógos, El concepto de téchnē y la crítica filosófica de la retórica», en Er, Revista de Filosofía, XV (1993), 9-42, pág. 31 y ss. La diferencia consiste en que Gorgias concibe la persuasión retórica como un engaño que se ampara en las debilidades de la opinión, mientras que Isócrates quiere rehabilitarla moralmente para ponerla al servicio de una retórica capaz de convertirse en instrumento de la acción política.

5 Cito la traducción de Guzmán Hermida, J. M., Isócrates, Discursos, 2 vols., Madrid, 1979. 
en la República ${ }^{6}$, es indudable que en esta obra Platón hace referencia al desprecio que los fundamentos científicos de una ciencia del gobierno provocaban en la época, a la vez que se posiciona frente a las pretensiones que albergaba la retórica de poder dirimir todas las cuestiones del estado sobre la base de los fundamentos epistémicos proporcionados por la dóxa. En la imagen de la polis descrita por Sócrates en el libro VI, en la que se compara el estado democrático ateniense con una nave, los marineros le disputan su control al patrón, que carece, como ellos, de conocimientos náuticos. La tesis que estos marineros mantienen es la misma que la cultura retórica representada por Isócrates: todos declaran que pueden pilotar la nave y que no existe un arte náutica que pueda enseñarse (cfr. 488b). Sócrates sabe que no es asunto baladí, pues afirma que estos marineros ambiciosos de alcanzar el poder están dispuestos a descuartizar al que diga que un arte así se puede enseñar (VI 488c). Para una gente de esta naturaleza, que desprecia los conocimientos náuticos necesarios para pilotar la nave, el experto, el piloto verdadero que conoce el arte del estado, es decir, el filósofo de la ciudad ideal descrita en la República, será siempre consi-

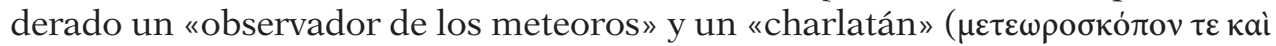
ả $\delta$ o $\varepsilon \dot{\sigma} \sigma \chi \eta v, 488 \mathrm{e} 4-489 \mathrm{a} 1)$. Con esta expresión Platón parece coger el guante que le lanzaba la concepción retórica del estado ${ }^{7}$, vigente en tiempos de Isócrates, para responderle partiendo de sus mismos términos y embarcándose en una tarea de demarcación del verdadero filósofo, que demostrara los derechos que le asisten a quien está dotado de un conocimiento superior. Frente a este modelo teorético, del que vamos a tratar, los conceptos que operan en el ámbito

6 Inmediatamente antes de referirse a estas prácticas propedéuticas, Isócrates menciona materias, como la astronomía y la geometría (Ant. 265.2), que difícilmente pueden aludir a otra cosa que al programa de estudios de la Academia platónica. Además, en un pasaje inmediatamente anterior, Isócrates nos recuerda que para la mayoría de los hombres ambas

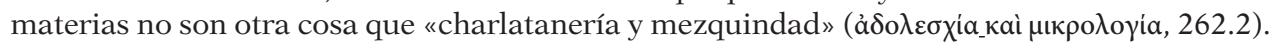

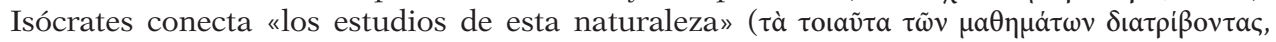
261.3-4) tanto con la astronomía y la geometría como con «los discursos erísticos» (261.2). En el Panatenaico esta asociación vuelve a repetirse, pues aquí se habla de estas ciencias y de los «llamados diálogos erísticos» sin solución de continuidad. Isócrates no niega la utilidad propedéutica de estos estudios, pero cree, como Calicles en el Gorgias (cfr. 484c), que deben limitarse a la juventud, pues no casan bien con la actividad propia de hombres que han llegado a la plenitud de su madurez vital (Panat. 28.1-2). No hay duda de que Isócrates se refiere en estos pasajes a las enseñanzas de la Academia, aunque posteriormente, como vemos, las haya juzgado con menor rigor que en su obra más temprana (cfr. In Soph. 8). En esto, por lo demás, estoy de acuerdo con Jaeger (citado en la n.2) y otros autores, cfr. DodDs, E. R., Plato, Gorgias, A revised text with introduction and commentary, Oxford (1959), 1990, p. 272. Sobre las relaciones entre Isócrates y Platón, véase la amplia nota de GIL, L., en Platón, Fedro, Madrid, (1959), 1970, p. XVIII-XXI y mi «Conflicto en torno al Lógos», ya citado.

7 Como hemos visto en la nota anterior, la expresión que aparece en Isócrates, aparentemente referida a Platón, es «charlatanería y mezquindad» (adoleschía kaì mikrología). En las Nubes de Aristófanes se presentaba también a Sócrates como una especie de sofista versado en los meteoros (v.228), y el personaje de esta obra, Estrepsíades, atribuye a la influencia de su

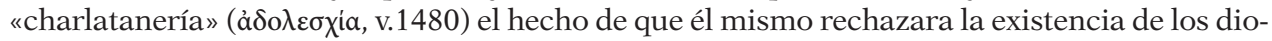
ses. Véase la traducción de Velásouez, O., Aristófanes, Nubes, Santiago de Chile, 2005, p. 112. 
de la retórica pertenecen a los dominios de la opinión y de ahí que Platón forje, como hemos visto, el término philódoxos, para hacer referencia a los ideólogos de la democracia ateniense, «amantes de los espectáculos y las artes», «los hombres de acción», cultivados en el discurso útil ${ }^{8}$ para intervenir en política, sin otro horizonte que las realidades de la experiencia ordinaria y los intereses de la mayoría culpable de haber llevado a la ciudad al desastre.

\section{El ARTE DEL ESTADo y LAS REFLEXIONES SOBRE EL SER}

La justificación de la figura del filósofo gobernante, contra las creencias generalizadas de la época y muy especialmente contra la retórica que consideraba imposible o inútil la ciencia filosófica del estado preconizada en la Academia, exigía por tanto demostrar la existencia de una facultad propia y un objeto correspondiente a ella que sirviera como criterio de demarcación del verdadero filósofo.

Platón encuentra esta pieza, susceptible de ser esgrimida en el debate contra

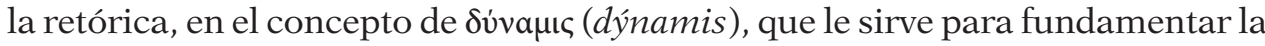
figura del filósofo, que será concebido como una especie de alter ego del orador entrenado en las artimañas de la retórica. La palabra en cuestión estaba vinculada en el Gorgias estrechamente a la retórica, porque venía a significar no solo las obras que esta puede ejecutar por medio de su arte ( $\tau \dot{\varepsilon} \chi v \eta$-téchnē, cfr. 447c, 456c, etc.), sino el poder que los oradores logran atesorar en las ciudades gracias a la capacidad de persuasión que aquella es capaz de conferir.

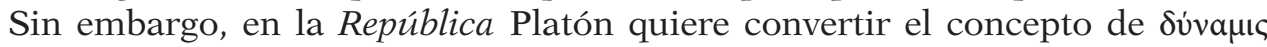
en una facultad específicamente intelectual, con un valor terminológicamente muy preciso que permita desgajar a la dóxa del ámbito del pensamiento cien-

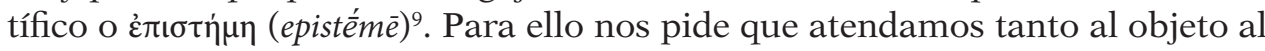
que está referida como a las operaciones que le son propias (477d1), es decir,

8 Existe una correspondencia extraordinaria entre las acusaciones de Isócrates y las críticas recibidas por la filosofía que Platón describe en la República: después de mencionar las materias propias del currículum académico, como «la astronomía, la geometría y otros estudios semejantes», y mencionar su calificación habitual como "charlatanería y mezquindad», Isócrates, hablando ahora con voz propia, hace hincapié en la inutilidad de tales conocimientos tanto para la vida privada como para la pública ( $c f r$. Ant. 262.3-4 y sgs.). De ahí que sostenga que no debe llamarse filosofía a una «actividad que no resulta útil para hablar ni para actuar» (266.2-3). Pero Platón, de la misma manera, cuando se refiere a los marineros que niegan la existencia de un arte de pilotar, sostiene que de existir en la nave el verdadero piloto, es decir, el filósofo gobernante, este sería considerado no solo un «miracielos y un charlatán» sino un «inútil» para lidiar con los problemas del estado (488e4-a1). Sobre Isócrates como probable alusión del término philódoxos, cfr. Vegetti, M., Platone, La Repubblica, libro V, traduzione e commento a cura di VegetTi, M., Nápoles, 2000, p. 103, n. 138.

9 Sobre la novedad terminológica que Platón confiere a la palabra en este sentido, véanse los comentarios ad loc. de Adam, J., The Republic of Plato, 2 vols., Cambridge, (1902), 1963 y Vegetti, M., locus cit. 
que la facultad se constituye como una potencia específica desde un doble punto de vista, tanto subjetivo como objetivo. Subjetivamente, la opinión y el conocimiento se distinguen en términos de falibilidad e infalibilidad. Platón no insiste mucho en esta ocasión en las razones que le asisten para establecer esta distinción, pero recordemos que el mismo Gorgias, a la hora de establecer en el Encomio de Helena los fundamentos de la persuasión retórica, había afirmado que la dóxa es «insegura e inestable»(82 DK B11) y que este estado de ausencia de saber, en el que «la mayoría toma a la opinión como consejera del alma», es el que hace posible el engaño de la persuasión operado por medio de la retórica. A este ámbito es al que pertenecen, según dice Sócrates, las «múltiples creencias que la multitud tiene acerca de lo bello» (479d4), punto de referencia obligado para que pueda tener lugar la manipulación característica lograda por la intervención de la retórica. El Sofista de Leontinos reconocía en el Gorgias que esta era la razón por la que la retórica podía reunir en sí misma, desde el punto de vista de su capacidad de persuasión, «todas las potencias» (Gorg. 456a8) propias de las artes específicas, ya que, amparándose en la verosimilitud de sus recursos persuasivos, podía aparentar ante el ignorante más sabiduría que el especialista o el experto competente. He aquí la potencia verdadera de la retórica y la razón de la amplitud universal que parece alcanzar: se trata de una técnica de persuasión que precisamente por operar a través de la dóxa no necesita adquirir el conocimiento de los objetos sobre los cuales ha de persuadir (Gorg. 459b-c).

Pero, en segundo lugar, esta dýnamis se distingue también en un sentido objetivo: la opinión tiene un objeto propio, que a juicio de Sócrates participa «tanto del ser como del no ser» (478d6) o, lo que es lo mismo, radica en un ámbito que se sitúa entre el no ser absoluto y lo que es en un sentido puro. Por el contario, en estricta correspondencia, el conocimiento se configura a consecuencia de ello como una dýnamis con un objeto propio, que versa sobre «lo que es» y tiene como contenido "conocer cómo es lo que es»(478a6). Se ha puesto en cuestión que la diferencia entre conocimiento y opinión pueda consistir en la existencia de objetos ontológicamente diferentes ${ }^{10}$. Sin embargo, en el Timeo, obra tardía en su carrera de escritor, la cuestión es tan clara que Platón parece haber basado en la diferencia entre la opinión verdadera y el saber una especie de razonamiento trascendental avant la lettre para justificar la existencia de las

10 Hay expresiones en los diálogos que permiten pensar que un mismo objeto puede ser el contenido cognitivo tanto de la opinión como del saber; cfr. Menón 98a, donde una opinión verdadera puede convertirse en ciencia con un «razonamiento causal». Algunos intérpretes han querido evitar una teoría de los dos mundos, especialmente en el contexto del libro V, donde Sócrates quiere persuadir a su oponente partiendo de sus propias convicciones. Este "requerimiento dialéctico» (FIne, G., "Knowledge and Belief in Republic V-VII», en EvERson, S. (ed.), Companions to ancient thought, Epistemology 1, Cambridge, 1990, 85-115, p. 87) exigiría pues hacer ver al adversario la diferencia entre la opinión y el saber sin necesidad de recurrir necesariamente a las formas. Para la tesis según la cual las formas no son el único objeto de conocimiento, véase también Annas, J., An Introduction to Plato's Republic, Oxford, 1982, págs. 192-215, esp. 210-211. 
ideas: «si la intelección y la opinión verdadera son dos géneros diferentes $<$ de conocimiento $>$, existen las ideas, que son en sí y por sí mismas, y no pueden ser aprehendidas por los sentidos, sino únicamente por medio del intelecto» $(\operatorname{Tim} .51 \mathrm{~d} 3-5)^{11}$. Otra cosa diferente es el ser que corresponde a este objeto inteligible, cuestión que examinaremos más adelante, y si con el reconocimiento de objetos diferentes ontológicamente Platón se vería abocado a una teoría de los dos mundos, que haría imposible transitar de uno al otro ${ }^{12}$.

Antes de pasar a este interesante problema, observemos que no es difícil hacerse una idea de la conexión que enlaza los dos aspectos, subjetivo y objetivo, de la dýnamis, aunque Platón no se haya pronunciado sobre ello. La falibilidad, inseguridad e inestabilidad propia de la opinión y las características inversas propias de la epistèmè se siguen de la naturaleza ontológica de los objetos correspondientes a cada una de estas dos facultades diferentes ${ }^{13}$. A juzgar por lo que sabemos de la Academia, es decir, de la importancia que tenían en su currículum los estudios matemáticos y teniendo en cuenta los ejemplos mismos mencionados por Platón (cfr. 479b, 510d), es muy probable que tuviera en mente a las matemáticas como el factum indiscutible que hacía pensar en un saber infalible y en una facultad independiente de la dóxa. El conocimiento matemático, por otra parte, no era puesto en duda por la cultura retórica, que admitía sus diferencias con la dóxa, aunque señalara su inutilidad para el arte del discurso. Ahora bien, la entidad inteligible en su pureza esencial, que constituye el objeto de la ciencia, permite la constitución de esta como un cuerpo de conocimiento seguro e infalible, bajo la forma de un sistema de teoremas en el que se expresen de forma categórica las propiedades y leyes por las que se rige el objeto en cuestión. El matemático considera objetos inteligibles, como

11 Estoy de acuerdo, por tanto, con Cornford, Plato's Cosmology, The Timaeus of Plato translated with a running commentary, Londres (1937), 1948, p. 190, cuando defiende la confluencia del libro V de la República con estos pasajes del Timeo, pues en ambos textos la existencia de las dos clases de objetos se sigue de la diferencia entre el conocimiento y la mera creencia. Es verdad que un dualismo excluyente es incompatible con muchos pasajes de los diálogos, pero en última instancia, para que haya conocimiento en sentido estricto, ya sea a propósito de un objeto sensible o de otra naturaleza, es necesario que este esté referido a las esencias puras que constituyen el ser de las ideas. Véase la discusión del problema en FERRARI, F., «Conoscenza e opinione: il filosofo e la città», en Platone, La Repubblica, libro V, traduzione e commento a cura di VegetTi, M., 393-419, p. 412, que concluye, después de discutir toda la evidencia disponible, que la distinción entre dóxa y epistèmēe, hace referencia «a un ambito di oggetti dotati di una natura peculiare».

${ }_{12}$ Si los objetos de conocimiento no pueden ser objeto de opinión y vice versa, dice Annas (locus cit., pág. 193), el filósofo viviría en un mundo cognitivo diferente del que corresponde al resto de las personas. Aunque no puedo ocuparme en la presente ocasión del espinoso problema de los dos mundos, lo que es incuestionable, teniendo a la vista la alegoría de la Caverna, es que el filósofo está llamado a descender al mundo de las sombras. Su tarea es interpretarlas a la luz del conocimiento que depende de la intelección de las formas correspondientes.

13 Cfr. mi nota a este pasaje en Platón, República, trad. de Eggers, C., introd. y notas de Vallejo Campos, Á., ed. Mondadori, Milán, 2012, p. 599, n. 83. 
el concepto de lo doble, la diagonal o el cuadrado en sí y, a la vista de estas entidades puras, pueden formularse teoremas indiscutibles e infalibles. Por el contrario, en el mundo de la opinión, la mezcolanza de los objetos considerados por ella, en los que se combinan cualidades, como lo bello, lo justo y lo santo con la adherencia accidental de sus contrarios, no es extraño que sirvan de extravío, incertidumbre y error a una mente que carece de criterios para discernir qué es lo bello o lo justo y las propiedades y características que de ello pueden verdaderamente desprenderse ${ }^{14}$. La cultura retórica no ponía en cuestión la existencia de la ciencia y sus diferencias con la dóxa, pero el intento de Platón consiste en ampliar su alcance de los objetos matemáticos al ámbito de la praxis, en la que lo Justo, lo Bello y lo Bueno (cfr. 476a) tienen una trascendencia decisiva para el arte del discurso. Si la perfección o la pureza esencial de los objetos matemáticos fundamentan la exactitud, la precisión y la infalibilidad de la ciencia, frente a la inconstancia, la falibilidad y la manipulación retórica permitida por la opinión, la extensión de este modo de ser tal a los objetos propios de la praxis permitiría la fundación de la filosofía como un saber riguroso llamado a ostentar el arte del estado.

La discusión con la retórica trae al primer plano del discurso lo que podríamos llamar una ontología del poder. ¿Quiénes deben ser jefes de estado, se pregunta Sócrates, aquellos, como los filósofos, que tienen a la vista «lo que se halla

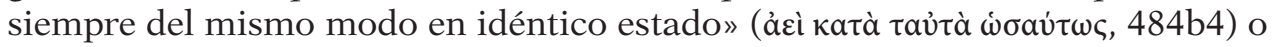
esos amantes de los espectáculos, que incurren en la errancia propia de los

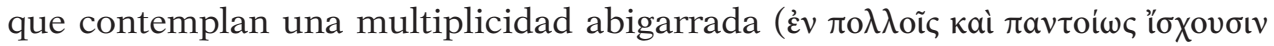

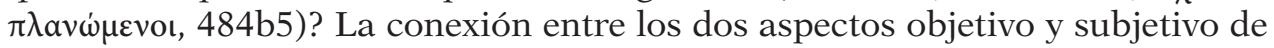
la dýnamis me parece irrefutable a la vista de los textos: como dijo Adam ${ }^{15}$, el gran comentarista de la República, «es la fluctuación del objeto la que hace que el sujeto fluctúe». Por eso Platón habla a menudo de estas variaciones e inconstancias propias de una posición «errante» como la de la opinión, que no puede llegar a ser conocimiento, porque su objeto es tò $\mu \varepsilon \tau \alpha \xi \grave{v} \pi \lambda a v \eta \tau \grave{v}$, es decir, una realidad intermedia, que va "errante entre el ser y el no ser» (479d9). Desde un punto de vista subjetivo, su ámbito está determinado por «las creencias de la multitud» y su objeto es una realidad intermedia entre «lo que no es y lo que es en forma pura» (479d, cfr. 477a7). Platón está dialogando con la retórica, retomando el aserto de Gorgias, que ampara el poder persuasivo del discurso en una opinión «insegura e inestable», pero va más allá de ella, porque está empeñado en proporcionar los fundamentos ontológicos en los que se basa este carácter de la dóxa. Su ámbito es el de la existencia fáctica de las cosas y este es un dominio, como hemos visto, que oscila entre unas cualidades y sus

14 Como indica Ferrari, F., «La verità del logos, vale a dire il suo essere completamente vero, dipende dall'essere assolutamente F del termine intenzionato», cfr. «Conoscenza e opinione: il filosofo e la città», en Platone, La Repubblica, libro V, traduzione e commento a cura di Vegetti, M., 393-419, p. 411, n. 18. Cfr. también, págs. 411s. y en este mismo volumen, «Teoria delle Idee e ontologia», 365-391, p. 381.

15 Cfr. Adam, J., ad loc. 
contrarias (479a-b), de tal manera que las cosas son a la vez bellas y feas, justas e injustas o buenas y malas. Su empeño está centrado en «apaciguar y convencer» (476e) a ese personaje que «ama las audiciones y los espectáculos» y «se deleita con sonidos bellos o con colores y figuras bellas», porque es incapaz de trascender el horizonte de prejuicios y facticidades en el que vive inmerso. A este conglomerado, tal y como podía hallarse representado por la sofística, la retórica y las prácticas socio-políticas de la sociedad ateniense, opone Sócrates como signo distintivo del filósofo llamado a gobernar una concepción normativa de la política basada en una idea esencial del ser.

Lo fundamental en esta polémica con la retórica consiste en establecer un criterio para la demarcación del verdadero filósofo, pero el carácter propio de este depende de la naturaleza específica del ser que es capaz de contemplar. Para adelantar mi posición diría que lo fundamental no es la existencia de los objetos considerados desde una y otra posición, sino el modo de ser que corresponde a ambos. La discrepancia con la retórica deriva en una concepción demarcadora del ser, porque el filósofo se mueve en una perspectiva normativa de objetos ideales puros: se trata de una alternativa a la concepción de la realidad que tiene «el amante del espectáculo» (ó $\varphi \iota \lambda o \theta \varepsilon \dot{\mu} \mu \omega v, 479 \mathrm{a} 3)$. Lo podemos llamar concepción demarcadora, porque este último viene a identificarse con el amante de la doxá (480a) y el filósofo se constituye frente a él gracias a ella. Hay quienes pretenden, como hemos dicho, que la diferencia entre la opinión y el conocimiento no implica necesariamente la existencia de objetos distintos, desde un punto de vista ontológico, sino diferentes conjuntos de proposiciones ${ }^{16}$, de tal manera que la opinión consistiría en un conjunto de proposiciones verdaderas y falsas, mientras que el conocimiento incluiría sólo proposiciones verdaderas. Pero a mi juicio se trata de objetos que difieren en su naturaleza esencial. Sócrates afirma en los textos a los que nos estamos refiriendo que la opinión tiene como objeto una multiplicidad de cosas que combinan caracteres contrarios, como lo bello y lo feo, lo justo y lo injusto, o lo piadoso y lo impío, pero estas multiplicidades se componen de objetos que "parecen» (479a7) tales o «podemos denominar» (479b7) o "decir» (479b10) que son así. El «parecer», «denominar» $\mathrm{y}$ "decir» podrían atribuirse, efectivamente, a un sujeto que expone estas operaciones en un conjunto de proposiciones, como si no afectaran al ser mismo del objeto de la opinión, pero a continuación el texto es más explícito y afirma de tales cosas que se ubican en un ámbito intermedio entre

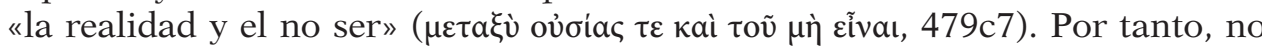
parece que estemos sólo ante un problema subjetivo, de modalidades de conocimiento que remiten a facultades distintas, sino también ante un objeto o, al menos, ante un carácter del objeto que se desprende del «eînai», del ser de la cosa en cuestión. Antes de esta afirmación Sócrates ha afirmado que el que conoce, conoce algo que es (476e).

16 Cfr. en este sentido, Fine, G., «Knowledge and Belief in Republic V-VII», en Everson, S. (ed.), Companions to ancient thought, Epistemology 1, Cambridge, 1990, 85-115, p. 91. 
Ha sido objeto de múltiples discusiones el significado de este ser que Platón aduce en estos pasajes como signo distinto del conocimiento que tiene el verdadero filósofo. Los comentaristas han distinguido un triple sentido: existencial, predicativo y verídico o veritativo-proposicional ${ }^{17}$. Lo que Sócrates comienza diciendo, como hemos visto, es que el que conoce algo, conoce algo que es (476e7), mientras que la ignorancia tiene por objeto lo que no es (477a10). Lo que no es en un sentido absoluto, a mi juicio, excluye no solo el sentido predicativo (lo que no es algo determinado) y el veritativo (lo que no es verdadero), sino también el existencial ${ }^{18}$. Pero una vez admitido que lo que es conocido es y lo que es objeto de opinión es y no es, tenemos que preguntarnos en qué sentido fundamentalmente «es» lo primero y «es y no es» lo segundo, pues creo que aquí radica el núcleo de la disputa de Platón con los amantes de los espectáculos que están a su juicio atrapados en la órbita engañosa de la dóxa. Desde luego, no hay que atribuir a Platón una nítida distinción entre la esencia y la existencia en sentido moderno, que probablemente constituiría un anacronismo, pero también me parece falso decir que Platón aún no distingue entre la

17 Unos autores han insistido más en alguno de estos sentidos que en otros. Como ejemplo de la interpretación existencial, véase Stokes, M. C., «Plato and the Sightlovers of the Republic», Apeiron, XXV (1992), 103-132, que prefiere un análisis más en términos existenciales que verídicos, aunque a su juicio se trata de un argumento dialéctico y, por tanto, no habría que atribuir a Platón las conclusiones a las que se llega en estos pasajes más allá de su «responsabilidad literaria» (p. 103). La interpretación predicativa del ser ha sido sostenida por muchos autores, entre los que debemos mencionar especialmente a Vlastos, G. ( Metaphysical Paradox» y «Degrees of Reality in Plato», en Platonic Studies, Princeton, 1981, 43-57, 58-75 respectivamente, que señaló especialmente el carácter "cognitivamente fiable» que tiene este sentido del ser; véase también Annas, J., An Introduction to Plato's Republic, págs. 196-200; Kahn, C., ha defendido, como otros muchos, el sentido predicativo cuando Platón se refiere a cosas que se hallan entre el ser y el no ser, aun insistiendo en el carácter verídico que acompaña al uso del verbo, véase "Being in Parmenides and Plato», La Parola del Passato, XLIII 1988, 237-261, p. 255 y sgs. y «Some Philosophical Uses of "to be" in Plato», Phronesis, XXVI, 1981, 105-134, págs. 112 y sgs. La interpretación mayoritariamente verídico-proposicional (en un sentido diferente de Kahn) ha sido esgrimida por Fine, G., en contra de la teoría de los dos mundos, loc. cit. También hay autores que insisten en la combinación de varios sentidos que se dan simultáneamente, por ejemplo, González, F. J. , ha sostenido la combinación de los sentidos predicativo y existencial, pues a su juicio para Platón el valor existencial de «es» no significa existencia como algo indeterminado en relación a la esencia, sino como una "existencia determinada», que por tanto combina la existencia y la predicación, cfr. «Propositions or Objects? A Critique of Gail Fine on Knowledge and Belief in Republic V», Phronesis, XLI/3, 1996, 245-275, págs. 260-1. Hay que tener en cuenta que el sentido verídico para algunos autores, como Kahn, tiene también un sentido objetivo, mientras que para Fine hace referencia a una propiedad de las proposiciones, de tal manera que para esta última la diferencia entre conocimiento y opinión comporta una diferencia entre conjuntos de proposiciones, pero no implicaría objetos ontológicamente diversos.

18 Afirma Kahn, C., que en $476 \mathrm{e}$ "ser (ón) no puede significar existencia, porque la afirmación de existencia ha sido efectuada mediante el contraste de algo ( $t i$ ) con nada (oudén)», cfr. «Being in Parmenides and Plato», La Parola del Passato, XLIII 1988, 237-261, p.255; véase también su discusión de estos pasajes en «Some Philosophical Uses of "to be" in Plato", Phronesis, XXVI, 1981 105-134, págs. 112 y sgs. 
sustancia de una cosa, o su mero estar ahí, como sujeto, «estando en un lugar y ocupando un cierto espacio", como dice en el Timeo (52b4), y sus propiedades, que pueden tener una mayor o menor consistencia esencial ${ }^{19}$. En el objeto de la opinión está implicada desde luego la existencia de algo porque sobre la nada ( $\mu \eta \delta \varepsilon \dot{v}, 478 \mathrm{~b} 8)$, dice Sócrates, no se puede opinar, hay que opinar sobre algo (ó

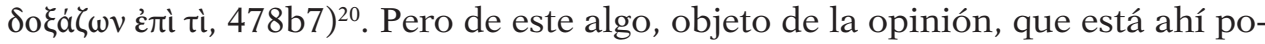
sicionado en la existencia, ocupando un lugar y un momento en el espacio y el tiempo, se dice a continuación que se halla en una situación «intermedia entre

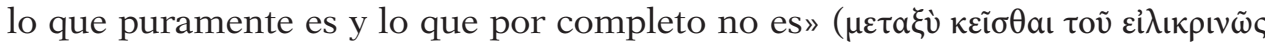

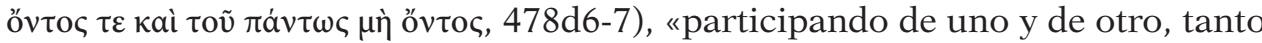
del ser como del no ser» (478e1-2). Creo que estoy en compañía de la mayoría de los especialistas, al atribuir a estos pasajes un sentido del ser diferente de la existencia, pues desde el punto de vista de la nuda existencia no tendría sentido alguno decir de una cosa que es y no es. Lo que Platón nos expone en estos pasajes, en correspondencia con su distinción entre el saber y la opinión, es una teoría de la gradación del ser, concebido desde un punto de vista esencial y no mera o principalmente existencial, porque no tiene sentido a mi juicio hablar de grados de existencia referidos puramente a la existencia ${ }^{21}$. «Más real», como dijo Vlastos ${ }^{22}$, no puede significar «más existente»: el verdadero conocimiento que ha de distinguir al filósofo tiene por objeto una realidad en la plenitud de su esencia, de la que dice Sócrates que es "plenamente cognoscible», porque «es plenamente» (

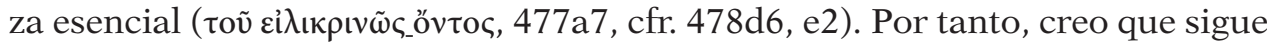
llevando razón Gilson cuando afirmó que, en contraposición a Platón, en las doctrinas en las que ser quiere decir existir, todo intermediario entre el ser y el no ser es difícilmente concebible ${ }^{23}$. Pero este es precisamente el contenido que corresponde a la dóxa, una realidad intermedia entre el ser y el no ser. Veamos sus características frente a las del objeto propio del saber.

Los amantes de las audiciones y los espectáculos son caracterizados negativamente por su rechazo de las formas o su incapacidad para contemplar lo justo, lo bello o lo bueno en sí (476a-c). De ellas se subraya en estos pasajes su unidad (476a) frente a la multiplicidad en la que se transforma su apariencia,

19 González, F., en su excelente artículo, en el que discute las posiciones de Fine, argumenta también contra Vlastos, afirmando que Platón no parece distinguir la «sustancia» de una cosa de sus "propiedades» o su existencia de su esencia de la manera que requeriría tal distinción (loc. cit., pág. 259).

${ }_{20}$ Cfr. sobre este punto en concreto, FerRARI, F., «Teoria delle idee e ontologia», p. 379.

21 Sigo estando de acuerdo con Vlastos cuando afirmó que no tiene mucho sentido hablar de grados de existencia, cfr. Vlastos, G., «Degrees of Reality», pág. 65. Para las críticas de las que ha sido objeto, véase González, F., loc. cit., pág. 259-260. No obstante, Vlastos no se olvida del valor existencial que pueda tener a la vez el ser, porque la afirmación platónica de que los amantes de los espectáculos tienen a la vista objetos que no son «realmente reales» «presupone su existencia» (loc. cit.).

22 Cfr. Vlastos, G., "A Metaphysical Paradox», p. 49.

23 Cfr. Gilson, E., El Ser y la Esencia, Buenos Aires, 1951, pág. 31. 
cuando entran en el mundo de la existencia fáctica de las cosas y «aparecen por doquier en comunión con acciones y cuerpos o combinadas entre ellas». Esta unidad de la forma (476a, 507b, 596a), que el amante de la presencia empírica de las cosas es incapaz de contemplar, es la otra cara de una identidad absolutamente homogénea propia de una realidad, que consiste en la perfección de la esencia. De ahí que se explique siempre la multiplicidad propia del objeto de la opinión en términos de unos particulares que son y no son a la vez buenos, bellos o justos. La atribución a tales multiplicidades de esa mescolanza entre el ser y el no ser suscita el comentario de Glaucón que recuerda los enigmas propios de los banquetes, en los que se habla del eunuco y el tiro al murciélago. El juego de palabras en cuestión es explicado por el escoliasta (Greene, 235): un hombre que no era un hombre (un eunuco), vio y no vio a un pájaro que no era un pájaro (murciélago), posado en un leño que no era un leño (caña), al que le arrojó y no le arrojó (tira sin acertar) una piedra que no era una piedra (piedra pómez).

Al igual que ocurre con los ejemplos a los que hace referencia Glaucón, las cosas que tiene a la vista el amante de los espectáculos están afectadas por una combinación de cualidades contrarias y de ahí que constituyan una multiplicidad. Cada una de ellas es bella en un sentido y fea en otra (479a6), porque cada particular es una combinación tal de características opuestas entre sí que puede ser denominada tanto con un nombre como con su contrario (479b7). Se trata de realidades empíricas afectadas con una ambigüedad que permite referirse a ellas utilizando descripciones alternativas completamente opuestas

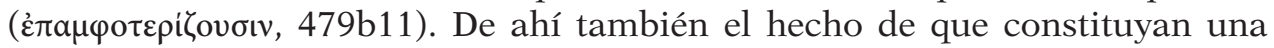
multiplicidad, pues, aun siendo bellas, registran entre sí múltiples diferencias, frente a la unidad de la idea, que es bella y solamente bella o lo que es lo mismo perfectamente bella. La multiplicidad es motivada por la diferencia que debido a esta específica combinación de cualidades contrarias registran los particulares entre sí, mientras que la idea o forma de belleza es una, porque comprende únicamente lo que conviene a la perfección de su esencia y es solo «lo que es». La perfección de las ideas se deriva de su unidad esencial y es el fundamento de una concepción normativa de la política que pretende juzgar las cosas no como son sino como deben ser.

En la formulación del argumento utilizado por los platónicos, «a partir de lo uno atribuido a una pluralidad», en la versión aristotélica que nos transmite Alejandro de Afrodisias, se insiste, efectivamente, para demostrar la existencia de las ideas en este punto: cada una de ellas expresa algo único e idéntico ( $\ddot{\varepsilon} v)$ que se predica de una multiplicidad de individuos sin que se identifique con ninguno de ellos ${ }^{24}$. El vocabulario técnico empleado por Platón para referirse al ser de las ideas, que se consolida en estos pasajes, después de haberlo empleado

24 Véase de la obra aristotélica Sobre las Ideas, el frag 3, especialmente las líneas 80.8 y sgs. del Comentario de la Metafísica de Alejandro de Afrodisias, trad. de Vallejo Campos, Á., Aristóteles, Fragmentos, Madrid, 2005, pág. 411s. 
ya en diálogos como el Fedón (aủtò tò ľoov, 74a, 75b, 78d) y el Banquete (aủiò $\kappa a \theta$ ' avitó, 211b), refleja lo que estamos diciendo: «La naturaleza de lo bello en

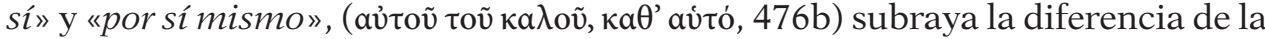
idea frente a las manifestaciones fenoménicas que participan de ella ( $\mu \varepsilon \tau \dot{\varepsilon} \chi o v \tau \alpha$, 476d). La diferencia radica en que los particulares tienen una existencia que no se identifica con la esencia que vienen a reflejar: de ellos podemos decir a la vez que son y no son buenos, bellos o justos. Por el contrario las ideas no son cosas que participan de la cualidad en cuestión sino que son la cualidad misma o la esencia de lo bello o lo bueno, por lo que su perfección como valores se desprende en realidad de su identidad esencial. Si se nos permitiera utilizar la distinción de esencia y existencia ${ }^{25}$, aún a sabiendas de su anacronismo e inexactitud, para esclarecer el sentido de esta diferencia entre los particulares y las formas, podríamos decir que a los particulares corresponde una existencia que participa defectuosamente de las esencias correspondientes, mientras que las ideas son esencias puras no contaminadas nunca por las circunstancias empíricas derivadas de la existencia fáctica de las cosas. En el texto se alude a ello cuando Sócrates afirma que hay que distinguir ontológicamente la semejanza de la identidad, porque no hay que confundir las cosas bellas que se asemejan a la idea de belleza con la idea correspondiente, que es la realidad misma de la belleza en sí $(476 \mathrm{c}-\mathrm{d})^{26}$.

El estado mental del que confunde ambos objetos se parece a la ensoñación, dice Sócrates (476c-d), al confundir algo que se asemeja a una cosa con la cosa misma. Sin prejuzgar acerca de la espinosa cuestión de la teoría de los dos mundos, parece ineludible reconocer que está en cuestión el problema de dos modalidades diferentes de conocimiento que se especifican como tales por tener objetos de diferente naturaleza: las cosas particulares existen, pero en un sentido predicativo o esencial del ser son y no son, y frente a ellas está el

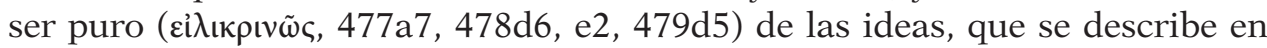
términos predominantemente esenciales o verídicos, como «aquello que es» («ö

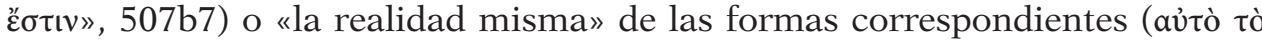

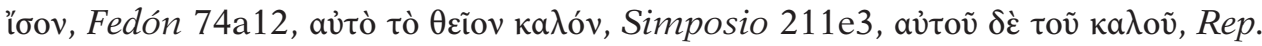
476b6). Como nos recuerda $\mathrm{Kahn}^{27}$, al comentar estos pasajes, en los que los particulares participan de cualidades contrarias, la construcción acentúa su valor predicativo, que no es independiente de su valor verídico, porque el ser tal de la forma F consiste en su ser sólo «lo que es» o en serlo verdaderamente,

25 Heidegger, M., Nietzsche, II, Barcelona, 2002 (trad. de J. L. Vermal) atribuye a Platón la separación del «que es» y el «qué es», el hóti y el tí (pág. 17), desde el momento en que «todo ente particular sólo deja que la idea aparezca en cada caso en tal o cual manera, o sea de modo limitado y menoscabado» (pág. 178). Esta dualidad entre el óntōs ón, el ser verdadero identificado con la idea, y el $m e \bar{e} o ́ n$, a medio camino entre el ser y el no ser, que es el ente particular, prepararía la distinción posterior que, «gracias a la interpretación teológica de la creación, aparece en múltiples formas», como la que se establece entre la essentia y la existentia (pág. 17).

26 Sobre este punto, cfr. Ferrari, F., loc. cit., págs. 372s.

27 KaHN, C., «Some Philosophical Uses of "to be” in Plato», págs. 113s. 
mientras que los particulares son a la vez F y no F, por lo que de ellos se puede decir a la vez que es tan verdadero como falso decir que son $\mathrm{F}$.

La diferencia entre la opinión y la ciencia tiene una dimensión subjetiva, pero comporta también, como estamos viendo, una naturaleza distinta en los objetos que le son propios. Algunos críticos han negado que se puedan separar el sentido existencial y el predicativo en el uso platónico del verbo ser, pues la existencia y la determinación de la cosa en cuestión van unidas inseparablemente, de manera que la noción de una gradación en el ser afectaría no sólo a la esencia sino a la existencia ${ }^{28}$. Pero a mi juicio está claro que, más allá de la posibilidad de separar ambos sentidos, la gradación no puede afectar al mero posicionamiento en el espacio y el tiempo de un particular, sino al modo en que refleja más perfecta o imperfectamente la cualidad de la forma correspondiente. Los grados de ser son proporcionales a la pureza de la esencia ${ }^{29}$ y el mismo Platón, al explicar el carácter intermedio entre el ser y el no ser que corresponde al objeto de la opinión, cita las multiplicidades de cosas bellas que a la vez se revelan como feas (479a-b). No niego que a los ojos de Platón cada una de estas determinaciones imperfectas de las cualidades correspondientes vaya unida a la existencia, pero el punto de vista que resulta decisivo para la distinción entre la opinión y el saber no es la existencia de los objetos, sino el modo en que estos poseen la cualidad en cuestión: lo que específica como tal a la facultad

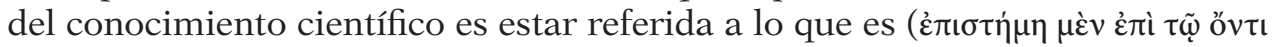
$\pi \dot{\varphi} \varphi v \kappa \varepsilon, 477 \mathrm{~b} 8)$ y de ello "conocer cómo es ${ }^{30}$. Es en este sentido predicativo del ser donde se juega la distinción entre la opinión y el saber: las múltiples creencias de la multitud ruedan, dice Sócrates, en este terreno intermedio (479d).

\section{LA POLÍtica, EL FILÓSOFo GOBERNANTE Y EL SER}

Me propongo a continuación mostrar la coherencia de una concepción del conocimiento que se basa fundamentalmente en la dimensión esencial del ser con el proyecto político que Platón expone en la República. La teoría de las formas establece una relación intrínseca, como hemos visto, entre el carácter infalible de la facultad cognoscitiva y el objeto que le corresponde. Esta relación se comprende fácilmente en los ejemplos matemáticos, como lo igual en sí mencionado en el Fedón (74a ss.) o la naturaleza del círculo en la Carta VII

28 Para González, F., loc.cit., pág. 261, la distinción entre lo predicativo y lo existencial depende de supuestos filosóficos que Platón no tenía por qué compartir. A su juicio, la noción de grados en la existencia no es absurda, sino que más bien lo es la noción de que un objeto sensible puede ser imperfectamente bello y sin embargo existir perfectamente.

29 Cfr. Gilson, E., loc. cit., pág. 32.

30 Como indica Kahn ( Some Philosophical Uses of “to be” in Plato», 113s.), la inter-

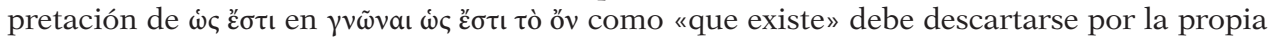

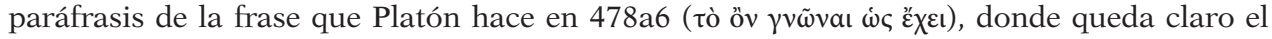
sentido predicativo: la ciencia está vertida sobre el ser para conocer de él «cómo es». 
(342c), pero Platón creó la teoría de las ideas pensando no sólo en las matemáticas, sino en el conocimiento político y moral. Los ejemplos lo ponen de manifiesto: la teoría no propone como objetos esencias matemáticas con más convicción de lo que lo hace en otros casos que pertenecen por entero al ámbito de la praxis, como lo bueno, lo bello, lo justo y lo santo en sí del Fedón (75c-d), la ciencia de la belleza en el Banquete (210d-e) o el paradigma que ha de residir en el alma del gobernante, según se dice en la República (484c), cuyo objeto es

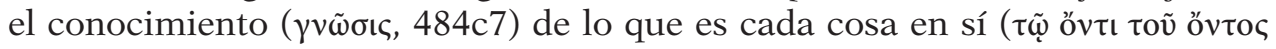

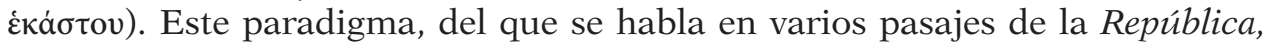
contiene "reglas concernientes a lo bello, lo justo y lo bueno» (484d) y puede servir para medir las diferencias que existen entre los philodóxoi, incapaces de rebasar el horizonte de las opiniones establecidas en el que se mueve la retórica, y el saber esencial del filósofo llamado a gobernar.

Analicemos, pues, este concepto del que depende el conocimiento del filósofo gobernante y con ello nada menos, según se dice en la obra (474b), que la posibilidad misma del estado ideal. Toda la discusión en torno a la justicia se ha llevado a cabo, afirma Sócrates, paradeígmatos héneka (472c4), es decir, con vistas a un paradigma. ¿Qué significado tiene esta palabra en la República? Lo primero que hay que decir es que el paradigma pertenece a los dominios del saber, porque su utilidad consiste en permitirnos «dirigir la mirada hacia lo más verdadero» (484c). De manera que su posesión nos ayuda a trazar la línea de demarcación entre el verdadero filósofo y el mero amante de la opinión. El guardián del estado ha de diferir del ciego (484c) y del que está soñando (476c)

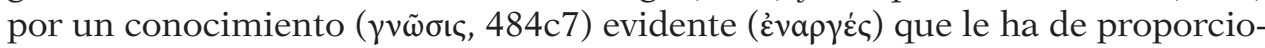
nar criterios para actuar. Pero «lo más verdadero» es una clara alusión al Bien, porque más adelante se dice que el filósofo gobernante se servirá de él como paradigma (540a). La tríada de valores en los que se fundamenta este saber, lo bello, lo bueno y lo justo (484d), deja fuera de toda duda a mi juicio que se trata de un conocimiento ideal, como el que se atribuye a la ciencia en contraposición con la concepción retórica de la dóxa.

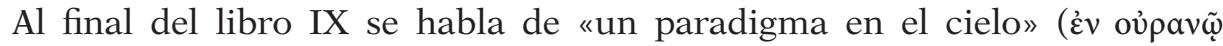
$\pi \alpha \rho a ́ \delta \varepsilon \imath \gamma \mu \alpha, 592 b 2)$ que ha de ser "para quien quiera verlo» la norma que le guíe en la fundación del estado. Se ha discutido mucho si este paradigma comporta el conocimiento de las ideas, porque algunos han señalado que hay que distinguir entre la idea de justicia y el modelo para la construcción de un estado justo, de tal manera que el paradigma no constituiría un modelo ideal, sino una especie de boceto empírico, como el cuadro que pinta un artista cuya belleza se deriva del arte del pintor ${ }^{31}$. Por otro lado, no ha faltado quien ha tomado la expresión «en el cielo» en un sentido literal y no meramente metafórico, por lo

31 Esta es la posición de Strauss, L., La Ciudad y el Hombre, Buenos Aires, 2006 (1964), pág. 176. A juicio de Strauss, «al buscar la justicia como modelo damos a entender que el hombre justo y la ciudad justa no serán perfectamente justos» (pág. 172), negando así el carácter ideal de la "ciudad justa», cuya condición se parecería más bien a la de un retrato de un ser humano que posee la belleza «en virtud del arte del pintor» (pág. 176). 
que el valor "geográfico» de la expresión excluiría que pueda tratarse de ideas, dado que estas no existen en el cielo, sino más allá de él ${ }^{32}$. Otros autores han afirmado, por el contrario, su carácter ideal como parádeigma katà phýsin ${ }^{33}$. A mi juicio, el cielo tiene un sentido metafórico y el paradigma no tiene nada que ver con la observación del cielo visible ${ }^{34}$, ya que a la astronomía se le ha atribuido un carácter meramente propedéutico y se ha afirmado anteriormente en la obra que ha de "abandonarse el cielo estrellado» (530b7), si se quiere que la observación astronómica preste algún servicio a lo que «hay de inteligente por naturaleza en el alma» (530c). El paradigma tiene más bien un carácter teórico normativo, pues de él debe extraer el filósofo gobernante, como hemos visto, normas sobre lo justo, lo bello y lo bueno. A mi juicio es enteramente ocioso discutir si el paradigma constituye una idea en sí o un instrumento de mediación entre la realidad ideal y el mundo de la existencia fáctica en la política, porque me parece indiscutible que en cualquier caso su punto de referencia y sus fundamentos son estos valores ideales que no son conocidos por medio de la experiencia ni extraídos de ella. La demarcación del filósofo gobernante frente al amante de la opinión se establece en el libro V sobre el fundamento de una concepción ideal del ser que no confunde la justicia mezclada con la injusticia, tal y como esta se encuentra en el mundo empírico de la retórica al uso, con la justicia en sí, que en la pureza de su entidad no contiene nada que sea contrario a ella. El paradigma, sea en sí mismo o no de carácter ideal, es el que permite al filósofo gobernante dirigir su mirada «a lo más verdadero» y contemplar «con la mayor precisión posible» (484c-d), de manera que lo mismo que el geómetra para lograr sus objetivos científicos debe pensar en el cuadrado y la diagonal en sí, el filósofo gobernante ha de tener ante los ojos los objetos ideales correspondientes, que, como lo justo, lo bello y lo bueno, son el fundamento de su modelo para la intervención en la vida pública.

Lo que nos importa subrayar para terminar es la coherencia del planteamiento político platónico con su ataque a la retórica y su propio ideal del saber. Creo que esto se pone de manifiesto perfectamente en la independencia frente al mundo de la existencia fáctica de las cosas que tiene el paradigma de la sociedad ideal dibujada en la República. Su rasgo más característico, a efectos de lo que venimos diciendo, es que se trata de una realidad cuya validez es independiente de la existencia e incluso de su posibilidad en el mundo

32 Cfr. Burnyeat, M., «Utopia and Fantasy: The Practicability of Plato's Ideally Just City», en Hopkins, J., Savile, A., eds., Pyschoanalysis, Mind and Art, Oxford, 1992, 175-87, pág. 177. En el Fedro 247c se habla de un «lugar supraceleste». Para Cornford, el cielo representa aquí «el orden visible del universo y particularmente de los cuerpos celestes, cfr. Corford, F. M., The Republic of Plato, Oxford, 1972 (1941), pág. 319 n.1 y Guthrie, W. K. C., Historia de la Filosofía Griega, vol. IV, Madrid, 1990, p. 520.

33 Isnardi Parente, M., «Motivi utopistici — ma non utopia- in Platone». en Uglione, R., (ed.), La Città ideale nella tradizione classica e biblico-cristiana, Turín, 1987, 137-154, pág. 140.

34 Cfr. Vegetti, M., «Il tempo, la storia, l'utopia», en Platone. La Repubblica. Traduzione e commento a cura di M. V., vol. VI, Libro VIII-IX, Nápoles, 2005, 137-168, págs. 160 n. 45 y 161 . 
de la experiencia. Platón afirma que si un pintor se propusiera «retratar como paradigma al hombre más hermoso» (472d5), la validez de su obra no quedaría mermada si no pudiese demostrar que «tal hombre puede existir» $(\mu \grave{\eta}$ हैхn

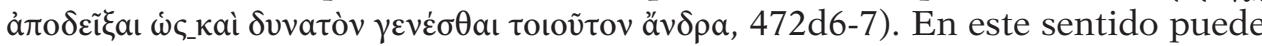
considerarse a Platón el fundador de la ontología que hace posible el discurso utópico ${ }^{35}$. Con esto no quiero decir que Platón contemple sus proyectos como meros "castillos en el aire» o que se trate de meras invocaciones y deseos (499c4-5), puesto que es él mismo el que explícita y repetidamente rechaza esta interpretación: el proyecto es posible no tal vez como si estuviera destinado a realizarse completamente, sino como algo que puede aproximarse a las propuestas formuladas $(473 \mathrm{a}-\mathrm{b})^{36}$, pero lo que está claro es que no resta validez a

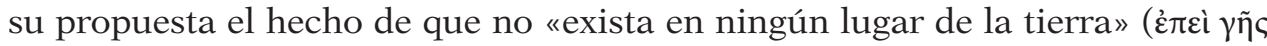

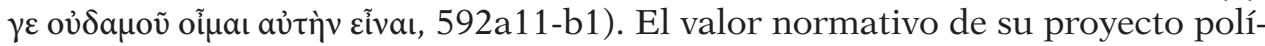
tico no queda menoscabado con la objeción de que semejante estado no puede

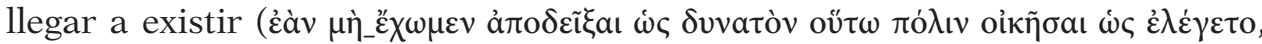
472e3-4). Con estas palabras Platón se aproxima máximamente en el concepto a la idea moderna de utopía, desde el punto de vista de que el filósofo ha de actuar con un ideal que no admite componendas con la realidad existente.

El paradigma reside en el cielo: lo que esto quiere decir es que a la vista del conocimiento esencial de las realidades contempladas por el filósofo, este no puede admitir un compromiso con lo que Kant llamó «una plebeya apelación a la experiencia» ni renunciar a su proyecto con el «mísero y contraproducente pretexto de ser impracticable». A juicio de Kant el proyecto platónico de la ciudad ideal representa un maximun que sirve de norma para aproximar «progresivamente la constitución jurídica de los hombres a la mayor perfección posible ${ }^{37}$. Poco importan aquí las circunstancias fácticas o las creencias y prejuicios contemporáneos entre los que ha de moverse el orador que se halla inmerso en las aguas turbulentas de la democracia ateniense y niega la existencia de un arte del estado.

El filósofo gobernante, dice Sócrates (592a), actuará «sólo en su propio estado, pero no en su patria, salvo que se presente algún azar divino». El filósofo, como comprende su interlocutor, no puede actuar salvo en los dominios de

35 Cfr. sobre este punto Vallejo Campos, A., «Nihilismo, Utopía y Conflicto de Valores», en Ávila, R., Estrada, J. A., Ruiz, E. (eds.), Itinerarios del Nihilismo, La Nada como Horizonte, Madrid, 2009, 41-61, págs. 45 y sgs. Sobre Platón, el pensamiento utópico y las interpretaciones de su pensamiento que han tendido a reconocer o rechazar esta dimensión de su proyecto político, véase Vegetti, M., «Un Paradigma in cielo», Platone Politico da Aristotele al Novecento, Roma, 2010.

36 Como indica Vegetti, M., Guida alla Lettura della Repubblica di Platone, Roma-Bari, 1999, pág. 73 y «Beltista eiper dynata». Lo statuto dell'utopia nella Repubblica, en VegetTI, M., Platone. La Repubblica, traduzione e commento a cura di M. V., vol. IV, Libro V, Nápoles, 2000, 107-147, págs. 121 y 138, la República no puede considerarse una utopía en el sentido de un castillo en el aire o una mera ensoñación, pero tampoco constituye un programa político de corto alcance que pueda ser llevado inmediatamente a la práctica.

37 Cfr. Kant, I., Crítica de la Razón Pura, trad. de P. Ribas, Madrid, 1978, págs. 311-112. 
este paradigma para la fundación del estado ideal que se halla sólo «en las

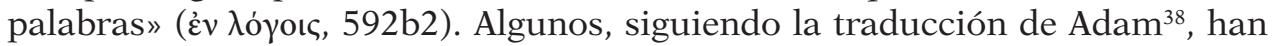
intentado despolitizar el contenido filosófico de la República, porque este consistiría en contemplar el paradigma en el cielo para que el filósofo funde una ciudad en su interior ${ }^{39}$. Si seguimos otras versiones, se trataría de que el filósofo mismo se «convierta en ciudadano suyo» y actúe en los estrictos márgenes de una teoría política de la justicia que contempla so lo la realidad esencial e ideal del ser y no las conveniencias acomodaticias de la vida diaria. Obsérvese pues la coherencia de un proyecto político que opone a la Realpolitik de la cultura retórica una concepción esencial de realidades ideales y que funda en ella las bases que legitiman la acción del filósofo-gobernante. Este proyecto lo podemos llamar tranquilamente utópico, no porque Platón considere irrealizable la política que tiene a la vista, sino porque se trata de un paradigma al que no le importa nada «si dicho Estado existe o va a existir en algún lado» (

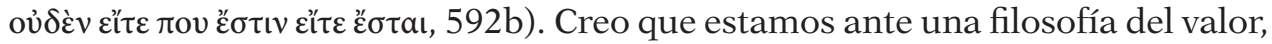
que rechaza el utilitarismo y la eficacia práctica exigidos por la cultura retórica y que, por el contrario, defiende la validez normativa de un ideal más allá de los compromisos derivados de la Caverna en la que normalmente transcurre la existencia humana. Desde un punto de vista metafísico, podríamos decir que el pensamiento utópico en Platón se construye sobre una ontología normativa ${ }^{40}$, que, como en tantos otros pensadores, confunde el valor con el ser y establece su esencia al margen de la existencia.

Universidad de Granada avallejo@ugr.es

Álvaro Vallejo Campos

[Artículo aprobado para publicación en noviembre de 2013]

38 La traducción del pasaje 592b propuesta por Adam, J., es la siguiente: «But perhaps it is laid up in heaven as an ensample for him who desires to behold it and beholding found a city in himself». Otros traductores (Shorey, Vegetti, Centrone, Morrison) proponen una traducción distinta ( «convertirse en ciudadano suyo»), que haría posible una interpretación más en consonancia con un significado político y no exclusivamente ético del pasaje. Véase nuestra nota 77 a este pasaje en Platón, República, ed. ya citada, págs. 709-711.

39 En este sentido, véase Griswold, C. L., «Le Liberalisme Platonicien, De la perfection individuelle comme fondement d'une théorie politique», en Dixsaut, M., Contre Platon, 2 vols., París, 1995, vol. II, 155-195, pág. 171; véase la discusión de estas posiciones que tienden a despolitizar el discurso filosófico de la República en Vegetti, M., «Plato senza politica», en Un Paradigma in cielo, págs. 145-159, esp. pág. 152.

40 Sobre la ontología normativa que Platón aplica en muchos casos, como el placer, el amor o la templanza, he tratado en otro lugar. Normativo se opone a descriptivo: a Platón no le interesa cómo la gente ordinaria entiende las cosas, el modo en que estas se manifiestan o su existencia fáctica en un momento determinado, sino cómo deberían ser a la luz de sus esencias correspondientes. Esta perspectiva se puede aplicar universalmente, como a mi juicio ocurre incluso en el caso del placer, cfr. Vallejo CAmpos, A., «The ontology of pleasure in the Philebus and the Republic», en Proceedings of the Boston Area Colloquium in Ancient Philosophy, XXIV, 2008, 51-74, págs. 51-2. 
